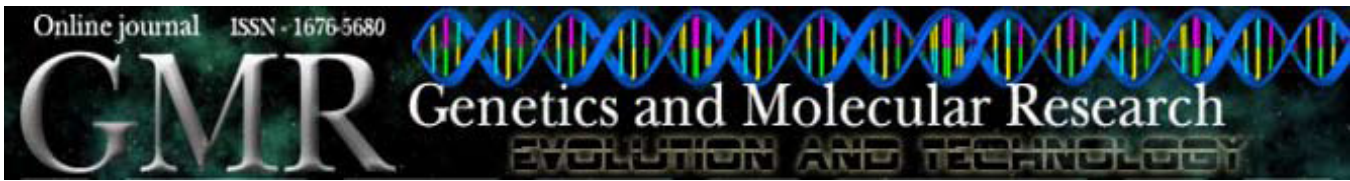

\title{
Single-primer PCR correction: a strategy for false-positive exclusion
}

\author{
J. Ma, P.W. Wang, D. Yao, Y.P. Wang, W. Yan and S.C. Guan \\ Biotechnology Center of Jilin Agricultural University, Changchun, P.R. China \\ Corresponding author: P.W. Wang \\ E-mail: peiwuw@yahoo.com.cn
}

Genet. Mol. Res. 10 (1): 150-159 (2011)

Received September 27, 2010

Accepted November 20, 2010

Published February 1, 2011

DOI 10.4238/vol10-1gmr988

\begin{abstract}
Polymerase chain reaction (PCR) technology plays an important role in molecular biology research, but false-positive and nonspecific PCR amplification have plagued many researchers. Currently, research on the optimization of the PCR system focuses on double-primer-based PCR products. This research has shown that PCR amplification based on single-primer binding to the DNA template is an important contributing factor to obtaining false-positive results, fragment impurity, and nonspecific fragment amplification, when the PCR conditions are highly restricted during PCR-based target gene cloning, detection of transgenic plants, simple-sequence repeat marker-assisted selection, and mRNA differential display. Here, we compared single- and double-primer amplification and proposed "single-primer PCR correction"; improvements in PCR that eliminate interference caused by single-primer-based nonspecific PCR amplification were demonstrated and the precision and success rates of experiments were increased. Although for some kinds of experiments, the improvement effect of single-primer PCR correction was variable, the precision and success rate could be elevated at 12$50 \%$ in our experiment by this way.
\end{abstract}

Key words: PCR; False-positive exclusion; Single-primer PCR correction 


\section{INTRODUCTION}

Polymerase chain reaction (PCR) technology has played a vital role in molecular biology research, but nonspecific PCR amplification occurs in almost all PCR-associated research. Research on primer annealing temperature, specificity, and template concentration has been conducted in order to determine the cause of fragment impurity, false-positive results, or nonspecific fragment amplification (Sahdev et al., 2007). Most of these issues can be avoided by optimizing the PCR system, but many researchers erroneously believe that all PCR products are the result of double-primer-based amplification.

Plant genomic and cDNA sequences are huge, making it impossible to precisely know the entire sequence in each single plant in an experiment. This inevitably introduces randomness to the process of primer design. Furthermore, because PCR primers are paired together for use in a single-PCR, the possibility exists that only one primer will bind to the genomic DNA or cDNA template and participate in the amplification process. We confirmed the phenomenon after manipulating rice Actin1 promoter gene cloning and detecting GUS and $35 S$ promoter genes of transgenic soybean.

Therefore, in this study, we conducted PCR-based target gene cloning, detected transgenic plants, conducted simple-sequence repeat (SSR) marker-assisted selection and mRNA differential displays, and demonstrated that the major cause of fragment impurity, false-positive results, or nonspecific amplification in PCR is single-primer amplification, even when all PCR conditions are highly restricted, including the use of DNA polymerases with high specificity and fidelity (such as PrimeSTAR HS DNA Polymerase). In addition, methods were developed for PCR improvement to eliminate unwanted "noise" caused by single-primer amplification and to increase the precision and success rate of experiments.

\section{MATERIAL AND METHODS}

\section{Material}

Soybean varieties JiNong17, JiNong18, and JiNong21, a root mutation variety of JiNong18, rice variety JiJing88, and genetically modified soybeans (GMS) were provided by the Biotechnology Center of Jilin Agricultural University. PrimeSTAR HS DNA Polymerase, dNTP mix, DNA Gel Extraction Kit, DNA Marker, Genomic DNA Extraction Kit, Total RNA Extraction Kit, and pMD18-T Simple Vector were purchased from TaKaRa (Dalian, China). The Plasmid Purification Mini-Kit and Southern Blot Kit were purchased from OMEGA and Roche (Shanghai, China), respectively. Other biochemical reagents, including acrylamide, methylene acrylamide, boric acid, ethylenediaminetetraacetic acid (EDTA), sodium hydroxide ( $\mathrm{NaOH})$, silver nitrate $\left(\mathrm{AgNO}_{3}\right)$, Tris (hydroxymethyl) aminomethane (Tris), urea, Tris base, ethidium bromide, agarose, yeast extract powder, and tryptone, were supplied by AMRESCO (USA).

\section{Primer design and PCR for rice Actin1 promoter}

Total DNA was extracted from JiJing88 rice leaf using the Universal Genomic DNA Extraction Kit, Version 3.0, according to manufacturer instructions (TaKaRa). Primers were designed for the rice Actin1 promoter sequence (GenBank accession No. S44221). 
Primer sequences were as follows: 5'-GCTAGCATACTGCAGGTCATTCA-3' (P1), 5'-CTGCAGTCTACCTACAAAAAAGCTC-3' (P2), with an expected amplified fragment length of $1150 \mathrm{bp}$. The reaction mixture for double-primer PCR amplification of the Actin1 promoter contained (50 $\mu \mathrm{L}$ total): $10.0 \mu \mathrm{L} 5 \mathrm{X}$ PrimeSTAR Buffer, $4.0 \mu \mathrm{L}$ dNTP mix $(2.5 \mathrm{mM}$ each dNTP), $1.0 \mu \mathrm{L}$ each P1 and P2 primer ( $20 \mu \mathrm{M}$ of each primer), $1.0 \mu \mathrm{L}$ genomic DNA template $(<1 \mu \mathrm{g}), 0.5 \mu \mathrm{L}$ PrimeSTAR ${ }^{\mathrm{TM}} \mathrm{HS}$ DNA Polymerase $(2.5 \mathrm{U} / \mu \mathrm{L})$, and $32.5 \mu \mathrm{L} \mathrm{ddH}_{2} \mathrm{O}$. Cycling conditions comprised 40 cycles of $98^{\circ} \mathrm{C}$ for $10 \mathrm{~s}, 55^{\circ} \mathrm{C}$ for $10 \mathrm{~s}$, and $72^{\circ} \mathrm{C}$ for $60 \mathrm{~s}$.

The reaction mixture for $\mathrm{P} 1$ single-primer PCR amplification of the Actin1 promoter contained (50 $\mu \mathrm{L}$ total): $10.0 \mu \mathrm{L}$ 5X PrimeSTAR Buffer, $4.0 \mu \mathrm{L}$ dNTP mix $(2.5 \mathrm{mM}$ each dNTP), $1.0 \mu \mathrm{L}$ P1 primer $(20 \mu \mathrm{M}), 1.0 \mu \mathrm{L}$ genomic DNA template $(<1 \mu \mathrm{g}), 0.5 \mu \mathrm{L}$ PrimeSTAR $^{\mathrm{TM}} \mathrm{HS}$ DNA Polymerase $(2.5 \mathrm{U} / \mu \mathrm{L})$, and $33.5 \mu \mathrm{L} \mathrm{ddH}_{2} \mathrm{O}$. Cycling conditions comprised 40 cycles of $98^{\circ} \mathrm{C}$ for $10 \mathrm{~s}, 55^{\circ} \mathrm{C}$ for $10 \mathrm{~s}$, and $72^{\circ} \mathrm{C}$ for $60 \mathrm{~s}$. Cycling conditions were the same as for double-primer PCR.

The reaction mixture and cycling conditions for P2 single-primer PCR amplification of the Actin1 promoter were the same as for P1 single-primer PCR.

\section{Primer design and PCR for 35S promoter and GUS gene in GMS}

Total DNA was extracted from GMS leaf using the Universal Genomic DNA Extraction Kit, version 3.0, according to manufacturer instructions (TaKaRa). Primers were designed for the rice $35 \mathrm{~S}$ promoter and GUS gene sequences on the pBI121 vector (GenBank accession No. AF485783.1). Primer sequences for the 35S promoter were as follows: 5'-AATATCGGGAAACCTCC-3' (P1), 5'-CTCCAAATGAAATGAACT-3' (P2), with an expected amplified fragment length of $317 \mathrm{bp}$. Primer sequences for the GUS gene fragment were as follows: 5'-GTGAATCCGCACCTCT-3' (P1), 5'-ATCGCCGCTTTGGACATA-3' (P2), with an expected amplified fragment length of $720 \mathrm{bp}$.

The reaction mixtures for single- and double-primer PCR amplification of the $35 \mathrm{~S}$ promoter and GUS gene fragments were the same as for the Actin1 promoter PCR. Cycling conditions for the $35 \mathrm{~S}$ promoter comprised 40 cycles of $98^{\circ} \mathrm{C}$ for $10 \mathrm{~s}, 46.5^{\circ} \mathrm{C}$ for $10 \mathrm{~s}$, and $72^{\circ} \mathrm{C}$ for $30 \mathrm{~s}$. Cycling conditions for the GUS gene comprised 40 cycles of $98^{\circ} \mathrm{C}$ for $10 \mathrm{~s}$, $72^{\circ} \mathrm{C}$ for $10 \mathrm{~s}$, and $72^{\circ} \mathrm{C}$ for $40 \mathrm{~s}$.

\section{Southern blot of GUS gene in GMS}

Southern blot hybridization of the GUS gene in GMS was performed with the use of the DIG DNA Labeling and Detection Kit, according to manufacturer instructions (Roche).

\section{Primer design and PCR for SSR markers}

SSR primer pairs were randomly selected for 8 individual SSRs (Satt100, Satt199, Satt225, Satt277, Satt354, Satt599, Satt636, and Satt690), from SSR primer sequences on the SoyBase and the Soybean Breeder's Toolbox website (http://www.soybase.org/).

The reaction mixture for double-primer amplification of Satt100 contained $(50 \mu \mathrm{L}$ total): $10.0 \mu \mathrm{L} 5 \mathrm{X}$ PrimeSTAR Buffer, $4.0 \mu \mathrm{L}$ dNTP mix (2.5 mM each dNTP), $1.0 \mu \mathrm{L}$ each Satt100 P1 and P2 primer (20 $\mu \mathrm{M}$ each), $1.0 \mu \mathrm{L}$ genomic DNA template $(<1 \mu \mathrm{g}), 0.5 \mu \mathrm{L}$ 
PrimeSTAR ${ }^{\mathrm{TM}} \mathrm{HS}$ DNA Polymerase $(2.5 \mathrm{U} / \mu \mathrm{L})$, and $32.5 \mu \mathrm{L} \mathrm{ddH}_{2} \mathrm{O}$. Cycling conditions comprised 45 cycles of $98^{\circ} \mathrm{C}$ for $10 \mathrm{~s}, 46.5^{\circ} \mathrm{C}$ for $10 \mathrm{~s}$, and $72^{\circ} \mathrm{C}$ for $30 \mathrm{~s}$.

The reaction mixture for single-primer amplification of Satt100 P1 contained ( $50 \mu \mathrm{L}$ total): $10.0 \mu \mathrm{L} 5 \mathrm{X}$ PrimeSTAR buffer, $4.0 \mu \mathrm{L}$ dNTP mix (2.5 mM each dNTP), $1.0 \mu \mathrm{L}$ Satt100 P1 primer $(20 \mu \mathrm{M}), 1.0 \mu \mathrm{L}$ genomic DNA template $(<1 \mu \mathrm{g}), 0.5 \mu \mathrm{L}$ PrimeSTAR $^{\mathrm{TM}}$ HS DNA Polymerase $(2.5 \mathrm{U} / \mu \mathrm{L})$ and $33.5 \mu \mathrm{L} \mathrm{ddH}_{2} \mathrm{O}$. Cycling conditions were the same as for doubleprimer PCR of Satt100.

The reaction mixture and cycling conditions for Satt100 P2 single-primer amplification were the same as for Satt100 P1 single-primer PCR.

The reaction mixture and cycling conditions for single- and double-primer amplification of Satt199, Satt225, Satt277, Satt354, Satt599, Satt636, and Satt690 were the same as for Satt100 PCR, with adjustment of the annealing temperature for each specific primer pair.

\section{Primer design and PCR for genetic differential display}

Anchoring primers and random sequence primers were designed. The sequences of anchoring primers were as follows: 5'-AAGCTTTTTTTTTTTA-3' (R1), 5'-AAGCTTTTTTTTTTTC-3' (R2), and 5'-AAGCTTTTTTTTTTTG-3' (R3). The sequences of random primers were as follows: 5'-TGCCGAAGCTTTGGTAGC-3' (L1), 5'-TGCCGAAGCTTTGGTCAG-3' (L2), and 5'-TGCCGAAGCTTGATTCCG-3' (L3).

Total RNA was extracted from the roots of JiNong18 and a JiNong18 root mutant, and first-strand cDNA synthesis was performed with the use of the RNAiso Reagent Kit, according to manufacturer instructions (TaKaRa). Precise quantitation of cDNA was performed using the nucleic acid/protein detector, followed by PCR using primer combinations of R1L1, R2L2, and R3L3.

The reaction mixture for the R1L1 primer combination contained (50 $\mu \mathrm{L}$ total): $10.0 \mu \mathrm{L}$ 5X PrimeSTAR Buffer, $4.0 \mu \mathrm{L}$ dNTP mix ( $2.5 \mathrm{mM}$ each dNTP), $1.0 \mu \mathrm{L}$ each R1 and R2 primer (20 $\mu \mathrm{M}$ each), $1.0 \mu \mathrm{L}$ cDNA template $(<1 \mu \mathrm{g}), 0.5 \mu \mathrm{L}$ PrimeSTAR ${ }^{\mathrm{TM}}$ HS DNA Polymerase $(2.5$ $\mathrm{U} / \mathrm{L}$ ) and $32.5 \mu \mathrm{L} \mathrm{ddH_{2 }} \mathrm{O}$. Cycling conditions were as follows: 40 cycles of $98^{\circ} \mathrm{C}$ for $10 \mathrm{~s}, 60^{\circ} \mathrm{C}$ for $10 \mathrm{~s}$, and $72^{\circ} \mathrm{C}$ for $60 \mathrm{~s}$.

The reaction mixture for $\mathrm{R} 1$ single-primer amplification contained (50 $\mu \mathrm{L}$ total): 10.0 $\mu \mathrm{L} 5 \mathrm{X}$ PrimeSTAR Buffer, $4.0 \mu \mathrm{L}$ dNTP mix (2.5 mM each dNTP), $1.0 \mu \mathrm{L}$ Satt100 R1 primer $(20 \mu \mathrm{M}), 1.0 \mu \mathrm{L}$ cDNA template $(<1 \mu \mathrm{g}), 0.5 \mu \mathrm{L}$ PrimeSTAR ${ }^{\mathrm{TM}} \mathrm{HS}$ DNA Polymerase $(2.5 \mathrm{U} / \mu \mathrm{L})$ and $33.5 \mu \mathrm{L} \mathrm{ddH_{2 }}$ O. Cycling conditions were the same as for double-primer PCR. The reaction mixture and cycling conditions for L1 single-primer amplification were the same as for R1 singleprimer PCR.

Procedures for single- and double-primer amplification for R2L2 and R3L3 primer combinations were the same as for the R1L1 primer combination.

\section{RESULTS}

\section{PCR amplification using single- and double-primers for the rice Actin1 promoter}

For rice Actin1 promoter cloning, the Actin1 double-primers (P1 and $\mathrm{P} 2)$ produced two fragments ( $a$ and $b$ ), the $\mathrm{P} 1$ single-primer produced two fragments ( $c$ and $d$ ), and the $\mathrm{P} 2$ singleprimer did not amplify a fragment. The lengths of fragments $a$ and $d$ were almost identical, 
while the lengths of fragments $b$ and $c$ were different. It is possible that the double-primer fragment mixed with some of fragment $d$ from the single-primer reaction (Figure 1). Fragment $a$ was extracted and ligated into the pMD18-T vector, the recombinant plasmid was transformed into Escherichia coli, and 10 individual bacterial colonies were selected for sequencing (Beijing Liuhe Huada). The results showed only one Actin 1 promoter sequence in the 10 sequenced samples, while the other nine were products of amplification using the P1 single-primer.

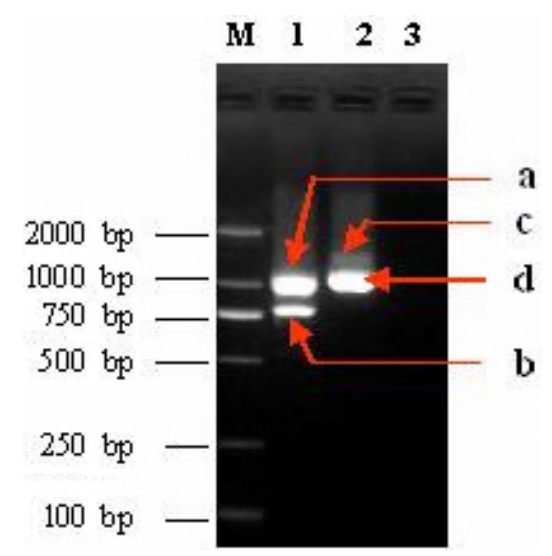

Figure 1. PCR amplification fragments using single- and double-Actin1 primers. $M=$ DNA marker DL-2000; lane $1=$ using double-primer (P1 and P2); lane 2 = using $\mathrm{P} 1$ primer; lane $3=$ using $\mathrm{P} 2$ primer.

\section{PCR amplification using single- and double-primers of the 35S promoter}

PCR detected the $35 \mathrm{~S}$ promoter in GMS samples, producing two fragments (I and II) from the double-primer reaction. Fragment I was nonspecific, while fragment II was the target product. P1 single-primer reactions produced fragment III, and the lengths of fragments I and III were identical, as shown in Figure 2. The nonspecific "noise" fragment from the 35S promoter reactions could have been the result of $\mathrm{P} 1$ single-primer amplification.

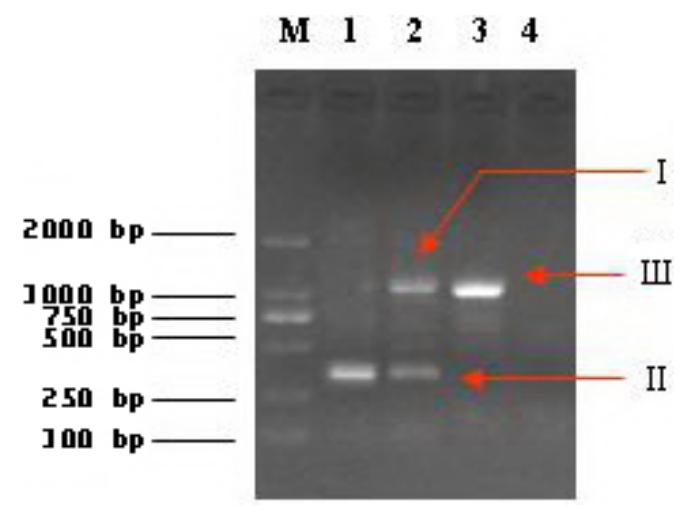

Figure 2. PCR amplification fragments using single- and double-35S primers. $M=$ DNA marker DL-2000; lane $1=$ positive control; lane $2=35 \mathrm{~S}$ fragment using double-primer; lane $3=$ fragment using $35 \mathrm{~S} \mathrm{P} 1$ primer; lane $4=$ fragment using 35S P2 primer; I = nonspecific fragment; II = target product; III = fragment III. For more details, see text. 


\section{PCR amplification using double-primers and Southern blot of the GUS gene}

PCR detected the GUS gene in GMS, producing fragments of the expected size (720 bp) in all plants, as shown in Figure 3. Southern blotting showed only one positive plant (fragment 3 in Figures 3 and 4). DNA fragments of each plant were extracted and ligated into the pMD18-T vector, and the recombinant plasmid was transformed into E. coli. Ten individual bacterial colonies were selected for sequencing from each Petri dish (Beijing Sanbo Yuanzhi). Only the sequence for one plant contained the target GUS gene fragment, and the sequences for the other plants were single-primer P1 amplification fragments (690-734 bp).

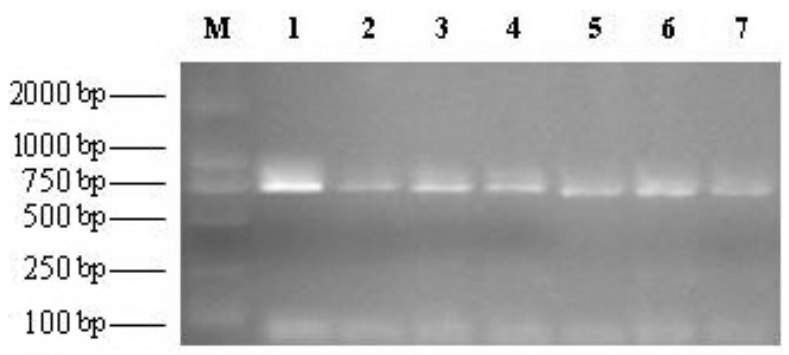

Figure 3. PCR amplification fragment using double-GUS primer. $M=$ DNA marker DL-2000; lane $1=$ positive control; lanes 2-7 = PCR amplification fragments using double-GUS primer.

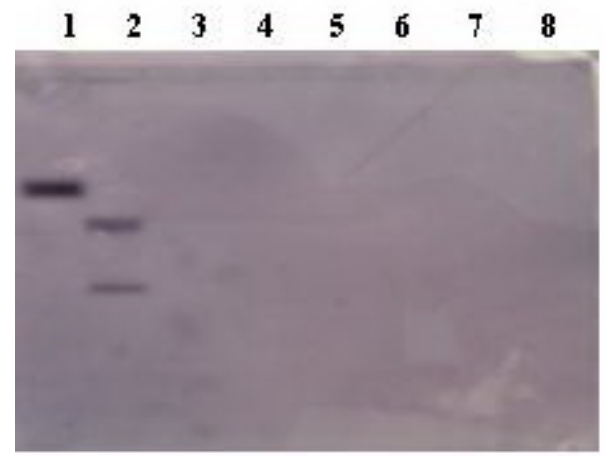

Figure 4. Southern blotting of transgenic soybean. Lane $1=$ Positive control; lane 2 = positive plant; lanes $3-8=$ negative plant.

\section{PCR amplification using single- and double-primers of SSR markers}

In soybean variety JiNong17, Satt225 single- and double-primers produced some fragments of identical length, as shown in Figure 5. Satt225 double-primer fragment $a$, from JiNong17, differed from fragments $c$ and $e$, obtained from Satt225 double-primer amplification in JiNong18 and JiNong21, respectively. Meanwhile, fragments $b$ and $a$ from Satt225 single-primer amplification in JiNong17 had an identical position on the gel, and fragments $d$ and $f$ from Satt225 single-primer amplification were identical in position to fragments $c$ and $e$ 
from Satt225 double-primer amplification in JiNong 18 and JiNong21 varieties, respectively. These results suggest that fragments $a, c$, and $e$ were contaminated by PCR products of singleprimer amplification reactions; otherwise, fragments $a, c$, and $e$ were the products of singleprimer amplification, namely $a=b, c=d$, and $e=f$. Sequencing results for fragments $a, b, c$, $d, e$, and $f$ showed that fragments $a, c$, and $e$ were contaminated by $b, d$, and $f$, respectively, indicating that fragments $a, c$, and $e$ were not pure target fragments from Satt225 double-primer amplification, but mixed with the fragments of single-primer amplification.

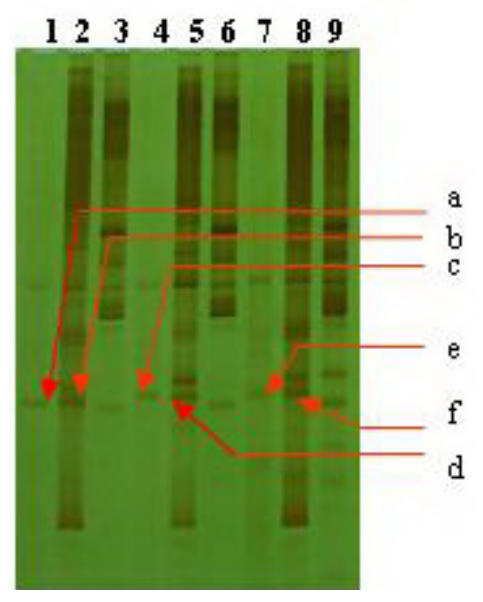

Figure 5. PCR amplification fragments using Satt225 single- and double-primers for JiNong17, JiNong18, and JiNong21. Lane $1=$ Using Satt225 double-primer for JiNong17; lane $2=$ using P1 primer for JiNong17; lane $3=$ using P2 primer for JiNong17; lane 4 = using Satt225 double-primer for JiNong18; lane $5=$ using P1 primer for JiNong18; lane $6=$ using P2 primer for JiNong18; lane $7=$ using Satt225 double-primer for JiNong21; lane $8=$ using P1 primer for JiNong21; lane $9=$ using P2 primer for JiNong21.

\section{PCR amplification using single- and double-primers for genetic differential display in JiNong18 and JiNong18 root mutant}

PCR amplification using R3L3 single- and double-primers produced fragments that were partially identical in size in JiNong 18 and JiNong 18 root mutant, as shown in Figure 6. Anchor primer R3 did not amplify any fragments, and random primer L3 produced multiple fragments. Of the differential fragments amplified using double-primers, fragment $a$ belonged specifically to the root mutant, but fragment $a$ from double-primer amplification was identical in length to fragment $b$ from single-primer amplification; conversely, differential fragment $c$ from double-primer amplification was identical in length to fragment $d$ from single-primer amplification in JiNong18, indicating that fragments $a$ and $c$ mixed with amplification products from L3 single-primer amplification; otherwise, fragments $a$ and $c$ were produced from L3 single-primer amplification, namely $a=b$ and $c=d$. Sequence results of fragments $a, b, c$, and $d$ showed that fragment $a$ mixed with fragment $b$, but fragment $c$ was identical to fragment $d$. This suggests that fragment $c$ is not the target product from R3L3 double-primer amplification, but rather the product from L3 single-primer amplification. 


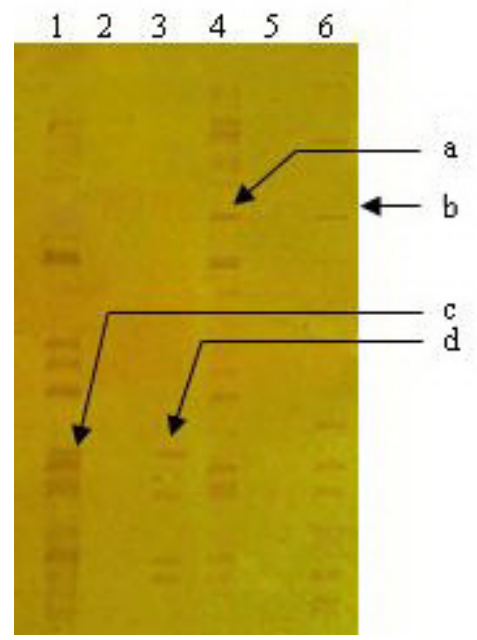

Figure 6. PCR amplification using single- and double-primers of R3L3 primer combination for JiNong 18 and JiNong18 root mutant. Lane 1 = Using R3L3 double-primer for JiNong18; lane 2 = using R3 single-primer for JiNong18; lane 3 = using L3 primer for JiNong18; lane 4 = using R3L3 double-primer for the root mutant; lane $5=$ using R3 single-primer for the root mutant; lane $6=$ using L3 single-primer for the root mutant.

\section{DISCUSSION}

PCR technology plays an important role in molecular biology research (Vallette et al., 1989; Ono et al., 2007; Wen et al., 2008; Löfström et al., 2008; Fabi et al., 2009). We found that even the use of strict PCR conditions can result in nonspecific amplification, false-positive results, and mixed single-/double-primer amplification fragments caused by single-primer PCR amplification. Paired primers tend to be selected to have similar annealing temperatures whenever possible, making single-primer fragment contamination difficult to overcome by optimizing PCR conditions. Further, false-positive results and impure fragments are inevitable, as demonstrated by the results, because single-primers can bind to genomic DNA or cDNA templates, and PCR using single-primers produces fragments that are indistinguishable from those obtained in double-primer PCR on agarose or polyacrylamide gel, under the same reaction conditions. It was further demonstrated that fragments of the target length may not have the correct sequence, with positive results from PCR giving negative results in Southern blotting (Ma et al., 2009), thereby increasing the possibility of a differential display reverse transcription-PCR false-positive.

Sequences obtained from target gene cloning are verified with gene sequencing. However, when recycling products mix with PCR products of single-primer amplification, randomness occurs, whether in direct gene sequencing of PCR products or sequencing through selection of single bacterial colonies after ligation into the pMD18-T vector and gene transfer. This factor could have serious effects on subsequent experiments. When using PCR clones of unknown sequences, there are few to no reference sequences with which to compare them (Colonna-Romano et al., 1998; Ghannam et al., 2005; Bozkurt et al., 2007); therefore, falsepositive results and single-/double-primer amplification fragment impurity caused by singleprimer amplification deserve consideration. 
After ligation into the pMD18-T vector and gene transfer, the molar counts of products with a larger grayscale exclusion were divided by the molar counts of products with a smaller grayscale, and single bacterial colonies were selected in the number at least over the mole ratio. The universal primer for the pMD18-T vector (such as M13, T7, and SP6) cooperating with the specific primers we designed was used to screen and remove false-positives (for example, if an upstream primer produces mismatches, downstream and universal primers can be used), and sequencing was then performed. The purpose of this method was to eliminate false-positive results and improve the precision of experiments.

In addition, we also found fragment contamination caused by single-primer amplification in the established SSR primers. Therefore, whether or not single-primer PCR correction should be performed on all established SSR primers needs consideration.

\section{CONCLUSION}

In practice, we found that PCR products from single-primer amplification were the largest cause of nonspecific fragments, false-positive results, and mixes of single-/doubleprimer fragments. Conventionally, it is assumed that all PCR products are the products of double-primer amplification, and there is no comparison between single- and double-primer amplification products. However, this is obviously a serious assumption that could cause many problems in research. Therefore, methods of determining single-primer amplification fragments mixed with double-primer PCR products are important to improve PCR precision and success rates. In this study, single-primers were used to detect nonspecific fragment amplification, false-positive results, and single-/double-primer amplification fragment impurity in PCR, a process called "single-primer PCR correction". This study suggests that, in PCR with genomic DNA or cDNA templates, single-primer PCR correction should be performed in order to determine whether the fragment obtained is the result of mixing or a false-positive result. When amplification fragments produced from single- and double-primers share the same position in a gel, sequencing cannot be conducted directly on double-primer PCR products, but instead, the single- and double-primer PCR products should be compared and the mole ratio estimated.

\section{ACKNOWLEDGMENTS}

Research supported by the National Natural Science Foundation of China (\#30971805) and the Young Scientists Foundation of JILIN Province in China (\#20100145).

\section{REFERENCES}

Bozkurt O, Unver T and Akkaya MS (2007). Genes associated with resistance to wheat yellow rust disease identified by differential display analysis. Physiol. Mol. Plant Pathol. 71: 251-259.

Colonna-Romano S, Porta A, Franco A, Kobayashi GS, et al. (1998). Identification and isolation by DDRT-PCR of genes differentially expressed by Histoplasma capsulatum during macrophages infection. Microb. Pathog. 25: 55-66.

Fabi JP, Lajolo FM and Nascimento JRO (2009). Cloning and characterization of transcripts differentially expressed in the pulp of ripening papaya. Sci. Hortic. 121: 159-165.

Ghannam A, Jacques A, De Ruffray P, Baillieul F, et al. (2005). Identification of tobacco ESTs with a hypersensitive response (HR)-specific pattern of expression and likely involved in the induction of the HR and/or localized acquired 
resistance (LAR). Plant Physiol. Biochem. 43: 249-259.

Löfström C, Axelsson CE and Rådström P (2008). Validation of a diagnostic PCR method for routine analysis of Salmonella spp. in animal feed samples. Food Anal. Method. 1: 23-27.

Ma J, Zhang J, Qu J, Wang YP, et al. (2009). Development of novel soybean germplasms with low activity of lipoxygenases by RNAi method. Sci. Agric. Sin. 42: 3804-3811.

Ono K, Satoh M, Yoshida T, Ozawa Y, et al. (2007). Species identification of animal cells by nested PCR targeted to mitochondrial DNA. In Vitro Cell Dev. Biol. Anim. 43: 168-175.

Sahdev S, Saini S, Tiwari P, Saxena S, et al. (2007). Amplification of GC-rich genes by following a combination strategy of primer design, enhancers and modified PCR cycle conditions. Mol. Cell Probes 21: 303-307.

Vallette F, Mege E, Reiss A and Adesnik M (1989). Construction of mutant and chimeric genes using the polymerase chain reaction. Nucleic Acids Res. 17: 723-733.

Wen ZX, Zhao TJ, Zhen YZ, Liu SH, et al. (2008). Association analysis of agronomic and quality traits with SSR markers in Glycine max and Glycine soja in China: I. Population structure and associated markers. Acta Agron. Sin. 34: 1169-1178. 